\title{
Virtual Reality Platforms for Education and Training in Industry
}

\author{
doi:10.3991/ijac.v2i2.870 \\ E. Blümel, W.Termath and T. Haase \\ Fraunhofer Institute for Factory and Automation, Magdeburg, Germany
}

\begin{abstract}
Developing, testing and operating complex machinery and repairing it under time pressure if it breaks down are some of the new skills professionals in many occupations have to learn as quickly as possible. Actions on machinery and plants are trained in individual lessons on an immersive virtual model. Lessons can be repeated as often as desired and independent of the real machinery's temporal and spatial constraints, without any risk to operators or the system if errors are made and even before the real system has been built. This paper introduces the methodology behind the technical solution and presents experiences acquired during its implementation with a virtual learning platform for operators and maintenance staff as examples.
\end{abstract}

Index Terms-Virtual reality platform, education, training, industry

\section{Motivation}

As product development times grow shorter, production starts up sooner, ranges of variants expand and process orientation intensifies, systematic optimization of the development and startup of complex production systems has become the prerequisite to saving time and money while simultaneously enhancing the quality of products and production processes. Shortened commissioning times for production systems particularly constitute a crucial criterion for time-to-market and time-to-volume. One fundamental aspect of the rapid startup and reliable operation of production systems is a company's competence, which is reflected in the qualification of every employee involved in the startup process.

Hence, any company's goal ought to be to provide suitable qualification measures to prepare future staff for impending tasks before a new production system starts up.

Such demands have generated a need for a flexibly configurable qualification platform that supports work on such tasks, factors in employees' different levels of knowledge and promotes cross-company information exchange. The Fraunhofer IFF's virtual reality (VR) learning platform meets all these requirements. The platform bundles knowledge on the startup and operation of production systems. Its methodological and didactic organization of tasks enables learners to acquire the knowledge necessary to startup and operate a system. The interconnectedness of complex relationships is reproduced and learners' interaction with the virtual work system requires them to actively handle tasks and solve problems on their own. Researchers from the Fraunhofer IFF have developed numerous cross-industry solutions for virtual interactive learning platforms for different training and educational objectives ([3], [5], [8], [10]).

Suppliers are also increasingly being integrated in product development as well as the construction, startup, operation and maintenance of technical systems. The machinery and plant manufacturing industry in particular frequently suffers from a lack of transparency and efficiency in intra-company order processing and project management. This entails investing substantial time and work in the necessary knowledge transfer between collaborative partners, which has to be organized in the phases of the product life cycle on the basis of new cooperation and communication strategies. Here too, virtual reality technologies hold potential to efficiently support collaborative partners' exchange of information on individual processes from assembly planning up through commissioning and production startup.

Virtual reality tools and technologies are already established in product development. As small and medium-sized enterprises have increasingly become involved in these processes, the pervasiveness and specific requirements of virtual reality technology in small and medium-sized enterprises has taken on particular importance.

A study conducted in 2007 by Fraunhofer IFF revealed that virtual reality technologies are being used over the entire productlifecycle ever more frequently: Sales support (86\%), manufacturing/assembly (86\%), development/factory planning (57\%) and maintenance/service (57\%). About $65 \%$ of companies that do not yet use VR cited intending to apply it to employee education and training (cf. [14]).

Nonetheless, small and medium-sized enterprises have problems establishing and operating the appropriate technical infrastructure on their own. SME cited information deficits and the excessive work and costs necessary to establish and operate the infrastructure for VR technologies as the main reasons for not yet using VR for education and training.

The Fraunhofer IFF Virtual Development and Training Centre (VDTC) provides machinery and plant manufacturers VR technology platforms to develop, test and apply methods and tools employing digital technologies for

- Virtual product development

- Virtual process engineering and

- Operation (education, operator training). 
These platforms are geared toward the product life cycle from development to production and up through application. The approach is unique because, instead of treating the stages consecutively and independently, it applies the tools and methods being developed to integrate the virtual technologies throughout all phases and especially to meet the needs of SME [11].

Based on data from machinery development and testing, the Fraunhofer IFF learning platform supports the qualification of future staff to operate and engineers to commission machinery long before it actually exists. Qualification focuses on operators and NC programmers as well as assemblers, maintenance engineers and service technicians, all of whom are provided learning platforms customized to their specific jobs [12].

\section{THE FRAUNHOFER IFF LEARNING PlATFORM}

\section{A. General concept}

The training concept upon which the Fraunhofer IFF learning platform is based allows customizing training to match future operators' levels of knowledge by variably configuring the level of difficulty on the basis of the level of interaction. A process to be learned can be explored initially in a model solution. First, learners are introduced to the entire process as well as its interactions with other subsystems. After that, learners are requested to execute the process, independently completing a task by interacting with the virtual system. The learning platform's system initially supports them by continuing to issue concrete instructions on completing the individual process steps. Afterward, learners ought to be able to execute the assigned tasks without the system's help. The learning platform logs all of a learner's activities as well as the time and number of attempts required to complete a task. This information is referenced later to assess training performance.

Enabling technical experts to also develop such qualification modules in their own companies necessitates suitable tools that are also easy to handle without expertise in programming. Complex virtual educational scenarios are generated with the aid of an authoring tool that models operations known from reality.

To create a virtual educational system accepted by learners and teachers and perceived as an effective addition to real training, a model must largely correspond to a real object's properties and visual appearance. To this end, real textures are employed to visualize complex plants. Causal relationships approximating a real system's properties can be modeled when it is rendered.

Such virtual educational scenarios can be used in a variety of virtual environments. An application on a laptop controlled by mouse and keyboard allows extreme flexibility in terms of time and location and takes advantage of familiar interaction metaphors. Its immersiveness (the sensation of immersion in a virtual world) is relatively minimal though. Environments like the immersive engineering workplace (Figure 1) make more intense immersion in a virtual environment possible.

\section{B. Interactive VR technologies for training}

The Fraunhofer IFF has developed a software platform that enables training and interaction with realistic virtual products, machinery and plants on the basis of 3D immersive virtual environments. A new technology has been produced that enables trainers to conduct and trainees to partake of theoretical and practical training on complex models individually and technical training in teams in distributed environments without having to revert to real objects. The recognition value of the visualization, the realism of the simulation of a product or plant's behavior and options for realistic user interaction are essential.

It is conceptually based on the precise objectives of the VR learning environment for the case of application and the methodical analysis of the skills to be learned (perception, orientation, skills, communication, etc.), users' personalities and learning styles and the structure of the course to teach the training objectives. The underlying concept is based on the methodical analysis of various assembly and maintenance tasks and classified features of applicable training environments based on virtual technologies that serve as the starting point for modeling a learning environment. This concept requires a supporting VR system architecture.

\section{The layered architecture}

A technical system must be modeled realistically to obtain realistic training conditions. Thus, a model should react and also respond to user actions just as the real equipment. Users must be enabled to perform every relevant action they would in the real world in the simulated environment (cf. [4]).

A great deal more information has to be modeled in addition to the objects' geometry, e.g. the hierarchy of objects and possible parenting relationships, constraints on movement, causalities, properties, actions and dynamic behavior. Furthermore, components are needed to enable trainees to evaluate their actions themselves and to facilitate communication between trainees and instructors.

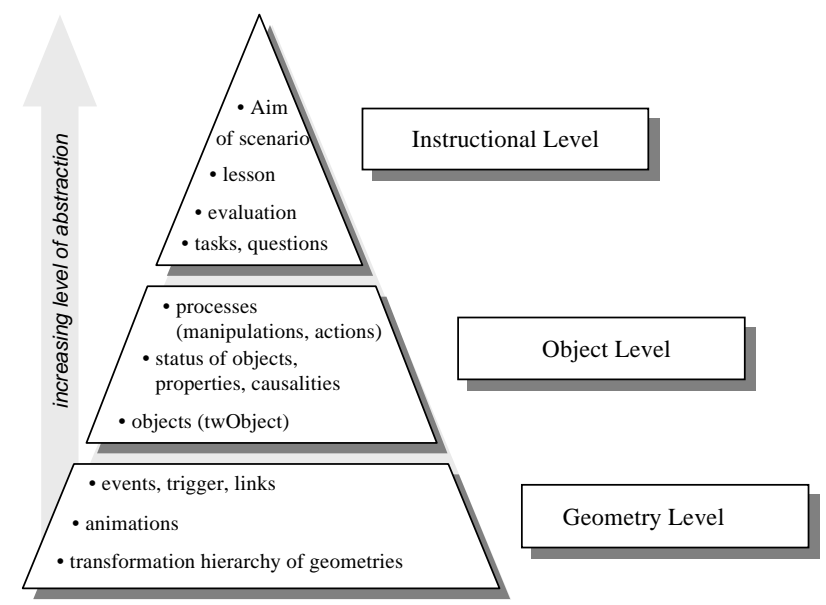

Figure 1. The levels of the VR scenario concept

The information needed to model a training environment can be divided into three levels (Figure 1).

\section{1) Geometry level:}

This level includes every type of node (geometry, animation, trigger, level-of-detail switches, etc.) common to the scenario structure of most existing VR systems. These entities provide the formal basis for implementing a scenario in a runtime system. Suitable converters import the information on this level from other systems such as 
CAD applications. Engineers, instructors and educators normally do not have to know details on these levels.

2) Object level:

This level is the domain of design engineers and contains the technological know-how specific to a system.

On the basis of the information from the geometry level, the object level specifies the basic objects that may be utilized in the next level to define training scenarios. Each object is comprised of a defined set of properties. The current values of all properties define a scenario's status. The entity of all possible scenario states is designated as the scenario's phase space. Technically, it is the cross product of the ranges of values of all object properties. A subset of the phase space is called a criterion. Typically, it is defined by logical conditions.

These layers provide the basis to simply define causalities between objects of all kinds. Generally speaking, a causality is a logical interdependence between property values of certain objects. A causality in this methodology consists of a criterion and an action. A criterion is the condition for the execution of an action. An action can be the assignment of property values, the start of an animation, the wait for a condition or the resultant invocation of other actions.

These layers can be utilized to model a wide variety of technical systems. At the same time, it minimizes or in some cases, completely eliminates the need for writing programming code.

The object level contains all information specific to a product already defined in the design process. It also includes characteristics determined by natural constraints, e.g. gravity, collision detection/prevention, etc.

\section{3) Instructional level:}

This level is the domain of educators or instructors. Objects defined on the object level can be utilized here to form training tasks. Training tasks can be used to construct lessons. One or more lessons may be necessary to attain a certain training objective.

All three of the aforementioned levels are interdependent and each level requires specialists from different fields.

It is important to emphasize the distinction between the levels of content (object level and educator level) and the level of the runtime system (geometry level) to retain the flexibility of the runtime system and the hardware platform. Moreover, this distinction allows focusing the structures that represent content on the requirements of a specific field of application. Otherwise, this would compel adapting the structures of the runtime system developed on the basis of entirely different premises and objectives. Since the information that describes a scenario is processed before the application runs, this distinction does not affect an actual simulation's performance.

Suitable tools that fulfill both the technical and functional and the pedagogical and didactic aspects of the content are needed to implement the substantial technical know-how required for existing technical options, cost effectively as well. To attain the high flexibility required by the applications developed, the components were divided

\section{4) Authoring system:}

The authoring system provides trainers support when they create training scenarios. The authoring system is intended to provide trainers a tool that requires a minimum of knowledge of computers. Unlike most training systems developed by computer experts, this application is intended to grant experts in the field of training diverse options for creativity.

- Scenario data: Work with the authoring system produces a training scenario saved as a scenario file containing the specific data for a concrete training task.

- Runtime system: The runtime system is essential to conducting training. It is independent of the concrete training scenario and can be equally applied to every scenario created with the authoring system. One runtime system instance is required for every trainer and trainee.

The information being modeled can generally be divided into the instructional, object and geometry levels. The creation of a virtual scenario requires significantly more extensive information than modeling geometry data, e.g. constraints on movement, assignments of object properties, descriptions of dynamic behavior or the compilation of training lessons.

Building upon this work, the Fraunhofer IFF developed tools that simplify the creation of training scenarios from the conversion of design data up through the creation of complex causal chains to define training objectives and generate training tasks even without knowledge of complex programming.

\section{Learning in VR work environments}

The thusly created scenarios are realistically oriented toward examples of real running processes. Users are given the most realistic impression possible when they interact with virtual models. In the virtual environment, they are able to complete every important manual action required to complete a task on the original object.

Among other things, a task includes names and descriptions of steps of a task, an initial situation, an objective (criterion for the success of the work performed), constraints to be observed (as criteria, the violation of which constitutes an error) and an ideal solution (procedure). Trainees are supported by different training modes (Figure 2), which require different activities [4]:

1) Discovery Mode

- Acquisition of background knowledge and experience by "playing around"

- No task, no procedure to be performed

- Freely manipulable visualization of a functioning system

\section{2) Presentation Mode}

The procedure demonstrates how professionals would complete the task at hand. The presentation is comparable to an interactive video in which users can determine their progress on their own. Users may diverge to acquire more details on specific topics and also select different viewpoints. 


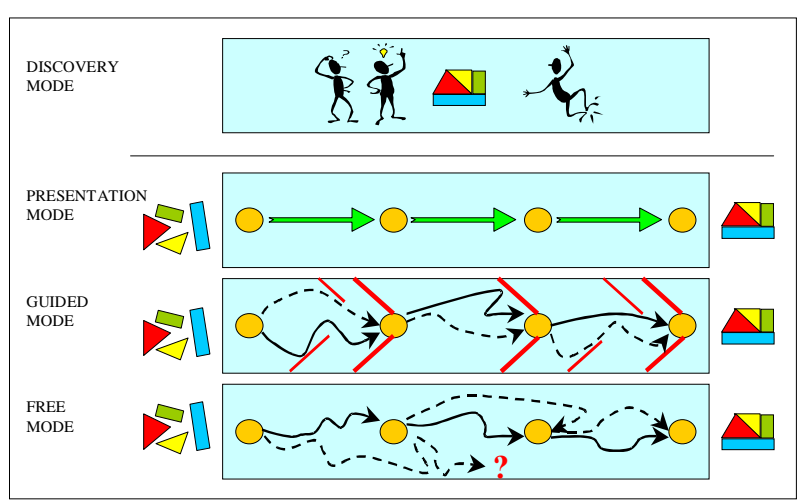

Figure 2. Training modes

\section{3) Guided Mode}

Applying the knowledge acquired in the presentation mode, the guided tour defines concrete tasks a trainee has to perform. The trainee receives hints and explanations related to the task. The system specifies the sequence of subtasks.

\section{4) Free Mode}

Trainees are not provided any specified procedure to complete the task. The training objective to be achieved emphasizes independent action and comprehension of causalities. Users may take advantage of free manipulation. They may make errors and the system evaluates them.

Numerous existing prototype solutions have demonstrated that the options for training staff with the support of virtual training systems hold great didactic and economic potential. The use of real machinery and plants for training frequently incurs considerable expenses. The creation of three-dimensional models during product development and plant engineering is very advanced in industry. Integrated utilization of design data not only for planning, development and manufacturing but also for the generation of VR systems provides a broad basis for their cost effective use in the widest variety of learning processes.

\section{Best PRACTICE EXAMPLES}

\section{A. Training in the machinery manufacturing industry}

Just as on the machinery manufacturing market as a whole, intensifying cost and time pressure and strict demands on product quality are increasingly shaping the manufacturing of large machining centers at Schiess $\mathrm{GmbH}$. Until now, such production facilities have been developed sequentially, the individual stages of development, e.g. mechanical design, electrical engineering and control system engineering, being implemented one after the other. Design errors made in preceding stages of development are often only discovered when the machine is actually commissioned. Eliminating these errors requires further iterative development cycles that consume time and money. Close attention is given to the stage of software development and testing, which is not completed until after the real machine had been built. Comprehensive and systematic software tests on a real machine prolong its commissioning time. This, in turn, is connected with increased costs. Time constraints usually preclude fully testing the software on the real machine.

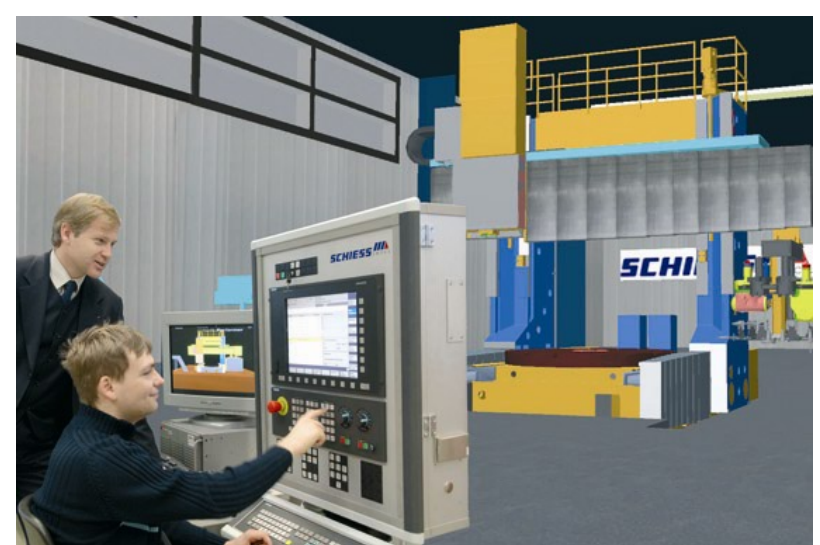

Figure 3. The real CNC used to interact with the virtual model

If the commissioning times for large machining centers are to be shortened, then the development process has to be parallelized with virtual models for instance. In the concrete example presented here, a virtual model imports existing 3-D CAD data, thus generating a kinematic model of the machine supplemented by a simulation of the machine's performance. Connecting real control components with the virtual tool machine integrated in the Fraunhofer IFF learning platform enables already starting the development of the control system in the virtual environment (cf. [11]). This allows control systems developers to perform complete software tests while a machine is still in production (Figure 3). Potential machine defects can be detected and eliminated early on. Thus, VR technologies can cut approximately $20 \%$ of the time previously required to commission new machinery.

The use of a virtual model in conjunction with a real control system is not only interesting for development. There are many and diverse applications in basic and advanced training. Since a virtual model reproduces the basic characteristics of machine performance and is controlled with an original operator panel, operators, NC developers and maintenance personnel can be given realistic training. Thus, a machine tool manufacturer can already furnish clients an authentic training environment while the real system is still being assembled. On the other hand, equipment operators can implement training for their operators at an early stage in an environment in which potential operating errors do not cause any damage to a real machine.

Future operators can explore and interactively learn every sequence of operations in best practice examples on a realistically recreated virtual model. A machine's sequence of operations and operating procedures are stored in its virtual model and can be trained easily by interacting in different virtual environments.

Training on a virtual model is not reliant on a real machine's availability and is thus dependent on neither time nor location.

\section{B. Virtual Interactive Training for RWE AG}

In the course of refining its internal training concept, RWE's Technik Center Primärtechnik (TCP) decided to collaborate with the experts from the Fraunhofer IFF Virtual Development and Training Centre VDTC.

The TCP specializes in high voltage equipment and large transformers and has been performing maintenance on power circuit breakers, converters, disconnectors and 
transformers with voltages of 110 to $380 \mathrm{kV}$ in its shops and on site at stations for over thirty years. To assure the quality of its work, employees receive comprehensive and intensive training. Qualification programs are supplemented by real-time information and technical support for employees throughout the entire concern.

The TCP and Fraunhofer IFF jointly developed interactive training scenarios (see figure 4) that were enthusiastically received by technical experts (cf. [13]). The specific constraints of ongoing technical operation, which make training in real situations quite difficult, were the reason for doing so.

One far-reaching problem is the relative impossibility of using sensitive equipment in operation, in this case transformers, for training for reasons of safety and because they are integrated in national or international power grid structures. Moreover, the pertinent safety regulations must always be strictly observed whenever inspection, servicing, maintenance and improvement work is being performed. This also complicates training considerably.

In addition, it is impossible to really observe functional processes inside equipment. Therefore, specialists need a high degree of technical knowledge and the ability to think abstractly to understand them.

In the end, the stations' decades-long service life necessitates developing the know-how of the technical specialists for the company and making it useful for future generations. This must be done as simply, vividly and standardized as possible.
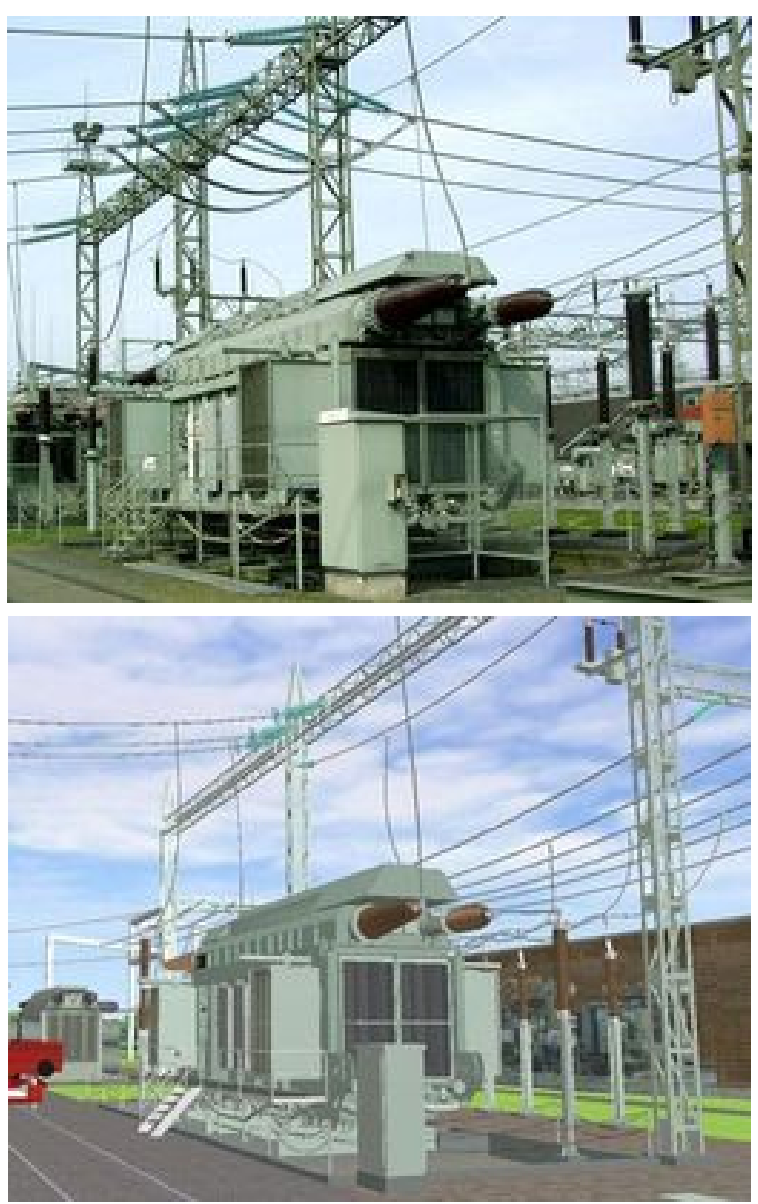

Figure 4. Comparison between real transformer and its virtual representation

\section{1) Preparation of a Transformer for Rail Transport}

The TCP uses a VR scenario of an extra high voltage grade power transformer of up to $200 \mathrm{MVA}$ in the $220 \mathrm{kV}$ capacity class. It shows interactive animations to train operators how to unplug it from the grid and disconnect the important elements (cf. [2]). These operations prepare the main transformer body for transportation and future use. The objective is for trainees to learn, train, comprehend and internalize the work procedures.

Given the high risks connected with the procedure, it is essential to demonstrate the correct sequential order of work incorporating safety regulations that guarantee safe conditions (cf. [2]). VR immerses trainees in realistic simulated environments. This can provide work experience without any risk of accidents or maloperation. Learning and interacting with VR is more efficient than traditional methods

A VR platform can import data in a variety of formats, e.g. 2-D and 3-D CAD. The parts of the transformer are designed with the requisite detail to ensure the function of the model mechanically and electrically and all the elements in the overall system. Figure 5 shows the usual work flow for creating a VR scenario.

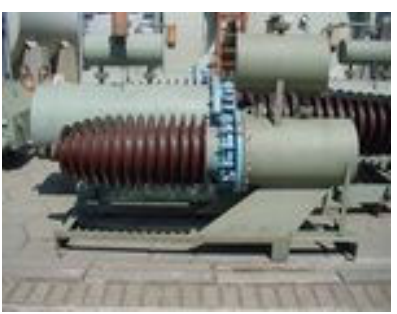

Photo

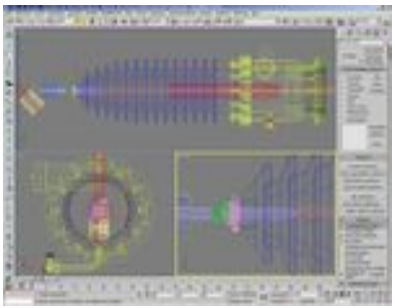

$3 \mathrm{D}$

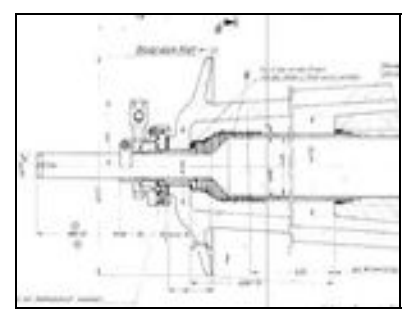

$2 \mathrm{D}$

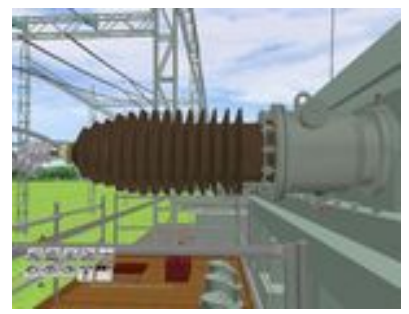

Animation
Figure 5. Work flow of the VR representation
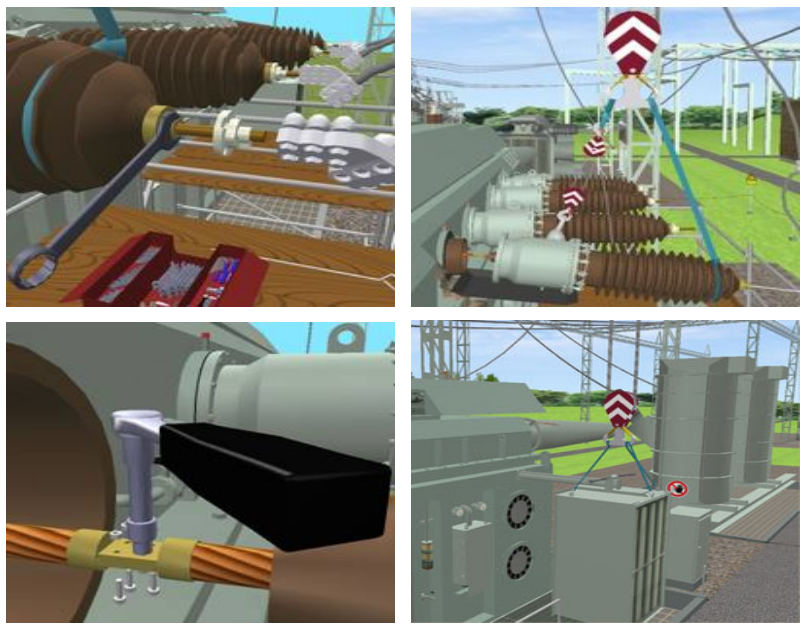

Figure 6. Steps of the work procedure 
A scenario's author may define three modes of training (presentation, guided and free) that smoothly transition from a low to a high level of interactivity on the basis of trainees' knowledge. The scenario for preparing the transformer for rail transport visualizes among other things the following working sequences: disconnecting primary circuit points, preparing transformer for work according to DIN VDE 0105-100, disassembly of diffusers and disassembly of ducts (see figure 6). VR is an excellent means to optimize typical industrial processes while improving safety by eliminating the potential for accident in high-risk maintenance operations and manufacturing processes. Learning and repeating procedures in a virtual environment reduces human errors and accidents.

\section{2) Replacing a Buchholz Relay}

Transformers are critically important equipment and their condition affects operations. A Buchholz relay is an important device that protects and monitors liquid cooled transformers and compensation reactors. It is easy to operate, highly reliable, maintenance free and long lived.

A relay is installed in the connecting pipe between the transformer tank and the conservator tank (see figure 7). In normal operation, it is filled completely with insulating liquid. The float is buoyed to its highest position. In reaction to malfunctions inside a transformer, a Buchholz relay collects the free gas present in the insulating liquid, leaks insulating liquid and discharges the insulating liquid flow induced by a pressure wave in the direction of the conservator tank.

The training covering the Buchholz relay teaches trainees:

- What a Buchholz relay's function in a transformer is

- How a Buchholz relay responds to a malfunction and

- How to replace/repair a Buchholz relay.

These three topics place different demands on the visualization and didactic treatment.

Visualizing the work steps executed to replace a relay necessitates a procedural approach. Realistically representing and precisely visualizing the operations facilitates comprehension and hones the ability to transfer practiced procedures to a real work situation.

The didactic treatment is crucial to teaching the function of a relay. Unlike assembly and disassembly, schematic elements (e.g. represented gas, overlaid arrows) can facilitate comprehension.

Existing 2-D educational materials and media from RWE and its equipment suppliers are integrated to optimally embed the 3-D visualization in the company's training and IT infrastructure. An integrated browser presents existing training materials such as operator manuals, 2-D animations and videos. A bidirectional connection between the VR scene and the browser contents allows systematically opening required information in the 3-D scene and additionally establishes a connection between the 2-D documentation (e.g. sectional drawing) and 3-D representation (see figure 8). In addition, supplementary information such as user guidance can be presented formatted as a graphic and adapted to the client's corporate identity and easily used through common forms of interaction (e.g. links).

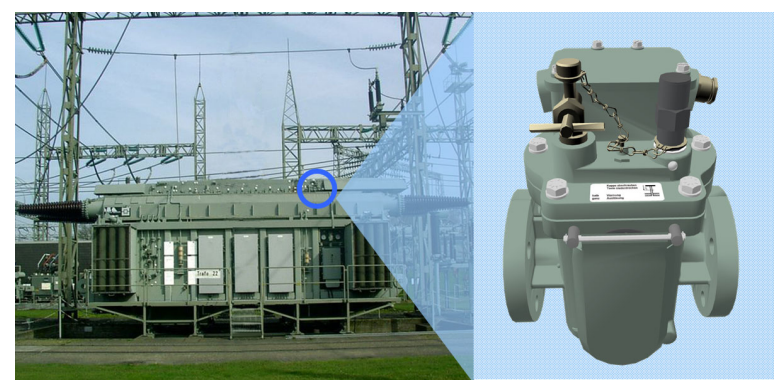

Figure 7. Buchholz relay in a transformer

\section{3) Making Empirical Knowledge Usable}

Empirical knowledge is bound to individuals and particular situations. As implicit knowledge, it is normally not available in a technically systematic structure.

Triad discussions are employed to explore valuable elements of experienced technical experts' knowledge. In individual discussions or at workshops, experienced experts (experts) report on specific work situations and identified problem solving strategies to younger colleagues (novices). Supervised by a layperson (moderator), the discussions are documented and evaluated. [6]

The solutions developed are visualized in a virtual scene, thus assuring this knowledge is secured and transferred. The solution developed combines established information available in a corporate process with a 3-D representation of a Buchholz relay. Existing documents (textual, videos, 2-D animations) are merged into one integrated system and may be utilized in a structured form.

Apart from enabling training on a system that is normally inaccessible, the use of virtual learning scenarios generates a whole series of other benefits.

Practical training can be conducted with a flexible number of trainees, largely any time and any place. Both the schedule for exercises and the focus on individual work steps may be varied as desired. Errors do not have any negative consequences in the virtual scenario, what is extremely important in safety relevant fields of application as in the TCP. Due to the demographic change processes, more and more young engineers get in those working processes. In this context the application of advanced technologies has proven to be an additional motivational factor for employees in the information age.

Not least, the system is also interesting to large concerns with an international base for another reason: Knowledge can almost always be transferred "culturally independently", i.e. as long as equipment of the same design is being used, standardized operations can be applied anywhere without any "translation problems".

\section{A Model to Evaluate VR LEARNing ENVIRONMENTS}

The findings on the use of such VR systems in learning and training programs are extraordinarily encouraging and indicate that while such VR systems cannot fully replace learning on real systems, they can substantially reduce requirements for system availability while simultaneously improving the results of learning. This makes it possible to reduce costs in many cases of application. At the same time, accessibility generates learning potentials that often cannot be developed with real systems at all or only to a limited extent (cf. [9]): 
- The didactic reduction of the complexity of modern work systems with VR systems considerably improves accessibility.

- Fast and slow motion increase clarity especially in processes that are imperceptible because of very brief time sequences or not accessible for learning processes at all or only with great effort because of very long time sequences.

- Influencing the level of networking supports a systematic orientation toward learning requirements.

- The transparency interactively implementable by learners can significantly enhance understandability and clarity normally unachievable on real systems.

- Learning actions are reversible and trainees can learn from their mistakes on VR systems without financial repercussions.

- Depending on the number of participants and the case of application (e.g. in hazardous environments). potentials to cut costs are extensive.

- Learning locations and times can be customized and flexibilized, thus, for example, making learning possible in a classroom without a real or accessible system.
However, businesses, educational institutions and the teaching materials industry require information verified by research on the cost/benefit ratio of learning in VR learning environments to develop secure investment and innovation strategies. Information on a few key issues significant for market-driven implementation of VR learning systems has not yet been verified, (cf. [4]):

- To what extent can skills directly utilizable in real work environments be developed and cultivated with VR based learning processes?

- What relationship must VR based learning processes have to learning sequences on real systems so that optimal learning arrangements can be assured?

- To what extent are the research findings acquired in prototype application situations transferrable to the acquisition of skills in other technical domains and, where applicable, in a narrower sense also to nontechnical domains.

- Based on the verified findings of research on learning, in what direction must the existing concepts for designing VR system environments, e.g. human-machine interface ergonomics, be developed?

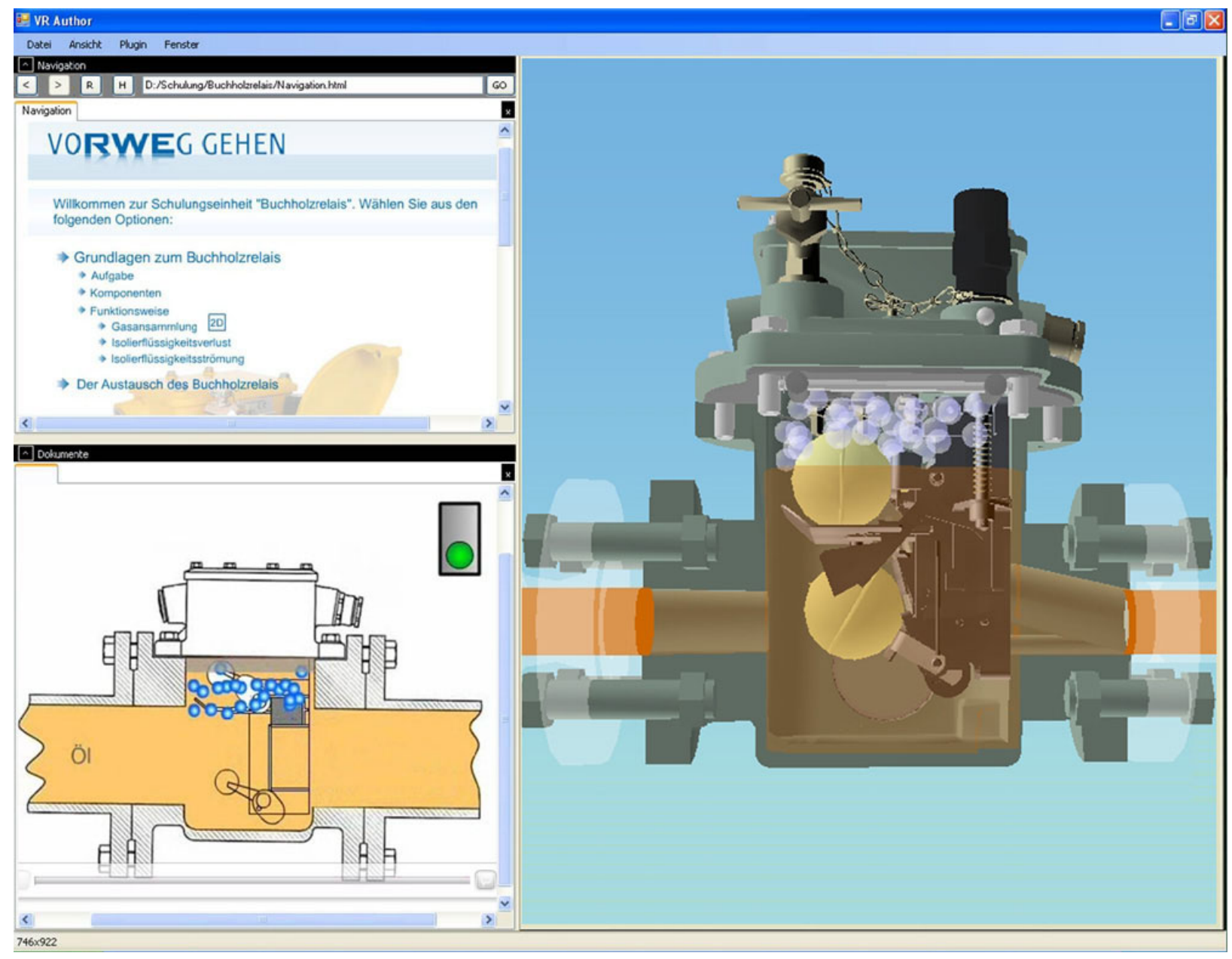

Figure 8. Integrated training system (left: 2-D representation, right: 3-D visualization 
TABLE I.

DOMAINS OF REALITY FOR LEARNING IN REAL AND VIRTUAL

\begin{tabular}{|c|c|c|c|}
\hline Domains of Reality & Real Work Environment & Virtual Work Environment & Didactic Consequences \\
\hline \multicolumn{4}{|c|}{ Contents } \\
\hline Complexity & $\begin{array}{c}100 \% \text { reduction at all times is often } \\
\text { impossible }\end{array}$ & $<100 \%$ reduction is always possible & $\begin{array}{l}\text { Didactic reduction of complex } \\
\text { environments }\end{array}$ \\
\hline Dynamics & $\begin{array}{l}\text { Extremely limited possibilities to } \\
\text { exert influence }\end{array}$ & $\begin{array}{l}\text { In principle, there are no constraints } \\
\text { on the exertion of influence }\end{array}$ & $\begin{array}{c}\text { Clarity through fast and slow } \\
\text { motion }\end{array}$ \\
\hline Networkedness & $\begin{array}{c}\text { Often unclear and only } \\
\text { conditionally influenceable }\end{array}$ & $\begin{array}{c}\text { Level of networking can be } \\
\text { influenced }\end{array}$ & $\begin{array}{c}\text { Systematically oriented toward } \\
\text { learning requirements }\end{array}$ \\
\hline Transparency & $\begin{array}{l}\text { Dependent on visibility and } \\
\text { accessibility }\end{array}$ & $\begin{array}{l}\text { Visibility and accessibility are } \\
\text { artificially extendable }\end{array}$ & $\begin{array}{l}\text { Better understandability and } \\
\text { clarity }\end{array}$ \\
\hline \multicolumn{4}{|c|}{ Learning Actions } \\
\hline Reversibility & $\begin{array}{c}\text { Rarely possible without } \\
\text { consequences (cost, time, material) }\end{array}$ & $\begin{array}{l}\text { Always possible without } \\
\text { consequences }\end{array}$ & Possible to learn from mistakes \\
\hline Cost-dependence & Learning actions always incur costs & $\begin{array}{l}\text { Higher costs for development but } \\
\text { lower costs for use }\end{array}$ & $\begin{array}{l}\text { Differentiation according to } \\
\text { number of participants and the } \\
\text { technology used }\end{array}$ \\
\hline Time-dependence & $\begin{array}{c}\text { Limited availability of work } \\
\text { process and system } \\
\end{array}$ & \multirow{2}{*}{ In principle, unlimited availability } & \multirow{2}{*}{$\begin{array}{c}\text { Customization and flexibilization } \\
\text { of learning times }\end{array}$} \\
\hline Location-dependence & $\begin{array}{l}\text { Always dependent on the work } \\
\text { environment }\end{array}$ & & \\
\hline
\end{tabular}

Jenewein (cf. [9]) has outlined a model to comparatively analyze the suitability of real and virtual work environments as the basis for learning processes. The elements of the analysis include:

- A differentiation between declarative and procedural knowledge (cf. [1]) as the basis for analyzing knowledge structures relevant for action;

- A model of domains of reality oriented toward information theory with which features of problemoriented learning can be applied to real and virtual work systems as learning environments (cf. [7]);

- Information on skills research to develop professional skills and research them in "real" job situations.

Based on these elements, the Magdeburg research team developed features for learning environments, which deliver a structural raster for research questions that make learning effort, didactic potential and success in real and virtual work environments comprehensible.

The structural raster excellently identifies and structures significant potentials connected with the use of virtual learning environments, which generates benefits on different levels:

- Didactic reduction facilitates the development of complex work systems for groups of learners with widely varying basic skills and knowledge.

- Fast and slow motion significantly increase clarity. Complex work systems are cognitively processed with a perception and understanding often impossible in real systems.

- The reversibility of learning actions and learning from mistakes allows learning processes with a calculable budget and risk potential.

- Time and location-independent learning is an important prerequisite to learning in learning environments resembling work processes. Customized learning times and locations enhance potential to develop skills in a lifelong learning process, e.g. through learning processes integrated in and supporting one's job.

For many work systems unavailable in industrial reality, VR developments hold new potential learning driven by work processes.

\section{SUMMARY}

Virtual reality technologies have experienced a sizeable leap in development in recent years. Extraordinarily complex realities can be reproduced with the aid of VR. The Fraunhofer Institute for Factory Operation and Automation IFF is home to interactive high-level VR environments that can be specially applied in a broad range of industrial training programs.

Both the basic technological and economic conditions will make broad use of interactive VR technologies in the basic and advanced vocational training of technical specialists possible in the near future. From the perspective of research, this is an impetus for research and development plans to intensify their focus on the potentials of learning in VR work environments. The technological developments presented here facilitate training on realistic virtual products, machinery and plants even when access to real objects, which are often not available for training at all or only to a limited extent, is limited. The use of VR systems in distributed learning environments is equally possible.

The theoretical construct constitutes the foundation for researching the didactic and technical potentials of implementing VR systems and their potentials for education. A conceptual theory for research on learning actions in real and virtual technical systems is being worked on.

The Fraunhofer IFF VDTC in Magdeburg's Port of Science is a vision become reality, namely to bring users, service providers and researchers together in one facility with state-of-the-art virtual reality technologies and 
infrastructures to develop innovative engineering and qualification solutions for real use.

In collaboration with the experts from the Fraunhofer IFF at the VDTC, customized learning platforms can be developed, tested and prepared for use. Training can be conducted out at a client's own facilities or in the VDTC's training rooms and labs such as the Elbe Dom, a 360 laser projection system with a projection cylinder, which has a diameter of $16 \mathrm{~m}$ and a height of $7 \mathrm{~m}$ (Figure 9).

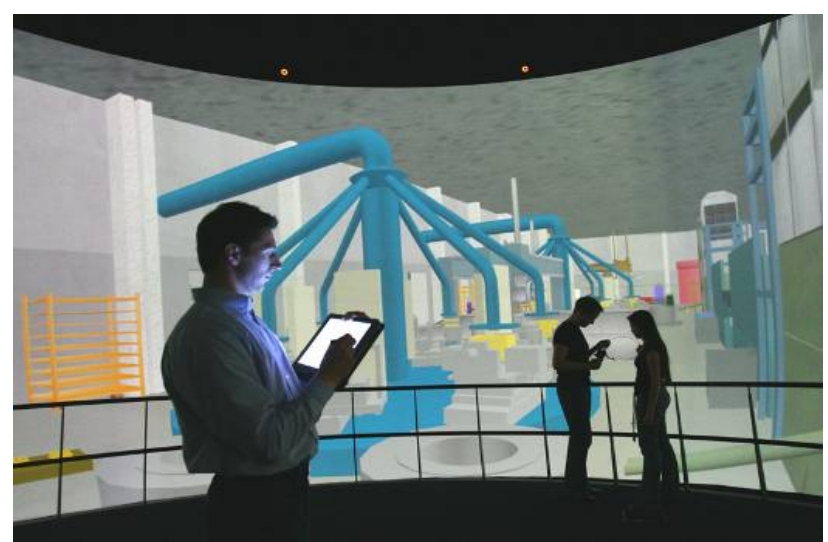

Figure 9. VDTC Elbe Dom immersive training center

\section{REFERENCES}

[1] Anderson, J. R. (1996) The Architecture of Cognition,. Veröffentlicht von Lawrence Erlbaum Associates, ISBN 0-80582233-X

[2] Arendarski, B., Termath, W., Mecking, P., (2008) Maintenance of Complex Machines in Electric Power Systems Using Virtual Reality Techniques, IEEE 2008, Vancouver, Canada, S. 483-487, ISBN: 978-1-4244-2092

[3] Belardinelli, C., Blümel, E., Müller, G., Schenk, M. (2008) Making the virtual more real: research at the Fraunhofer IFF Virtual Development and Training Centre. Journal Cognitive Processing, Springer Verlag, S. 217 - 224, ISSN 9217-224

[4] Blümel, E., Jenewein, K. (2005) Kompetenzentwicklung in realen und virtuellen Arbeitsumgebungen: Eckpunkte eines Forschungsprogramms. In: Schenk, M. (Hrsg.): Virtual Reality und Augmented Reality zum Planen, Testen und Betreiben technischer Systeme. Magdeburg: IFF, 177-182

[5] Blümel, E. (2007) Stand und Entwicklungstrends des Einsatzes von VR/AR-Techniken für Qualifizierung und Training im Arbeitsprozess. In: Gesellschaft für Arbeitswissenschaft e.V. (Ed.), Bericht zum 53. Arbeitswissenschaftlichen Kongress, Dortmund: GfA-Press, S. 241-244, ISBN 978-3-936804-04-1
[6] Dick, M., Wehner, T. (2008) Triadengespräche als Methode zum Austausch erfahrungsbasierten Wissens zwischen Experten und Novizen.. Gesellschaft für Arbeitswissenschaft e.V., 54. Arbeitswissenschaftlicher Kongress, München, S. 349-353, Dortmund, GfA-Press

[7] Dörner, D. (1987) Problemlösen als Informationsverarbeitung. Stuttgart: Kohlhammer ISBN 317001353X,

[8] Hintze, A., Schumann, M., Stuering, S. (2000) Employing Augmentation in Virtual Environments for Maintenance Training. Proceedings of the Industry/Interservice Training Simulation and Education Conference (I/ITSEC), November 26 - December 1, 2000, Orlando, FL/USA

[9] Jenewein, K., Schulz, T. (2007) Didaktische Potentiale des Lernens mit interaktiven VR-Systemen, dargestellt am Training des Instandhaltungspersonals mit dem virtuellen System „Airbus A 320“; In: Gesellschaft für Arbeitswissenschaft e.V. (Ed.), Bericht zum 53. Arbeitswissenschaftlichen Kongress, Dortmund: GfA-Press, S. 323-326, ISBN 978-3-936804-04-1

[10] Schenk, M. (2006) Virtuelle Realität - Trends und Anwendungen für die Zukunft. In. Schenk, M. (Ed.): Wettbewerbsvorteile im Anlagenbau realisieren. Zukunftsszenarien und Erfahrungsberichte. Tagung Anlagenbau der Zukunft. Magdeburg, 97-103.

[11] Schenk, M., Blümel, E., Schumann, M. and Böhme, T. (2006) Virtuelle Werkzeugmaschinen real gesteuert, In: wt Werkstattstechnik online Vol. 96, Issue 7/8.

[12] Schenk, M., Blümel, E. (2007) Lernplattformen zum Anlauf und Betrieb von Produktionssystemen. Industriemanagement Zeitschrift für industrielle Geschäftsprozesse, Heft 3, S. 23 - 26, ISSN 1434-1980

[13] Termath, W., Mecking, P. (2007) Virtuell-Interaktives Training für RWE, IFFocus Mensch-Maschine interaktiv 2/2007,, Magdeburg, S. 22-25, ISBN: 978-8167-7537-9

[14] Urbansky, A.; Schumann, M. and Bitterlich, M. (2007) Fachvortrag „Einsatz von VR/AR-Technologien in kleinen und mittleren Unternehmen den Maschinen- und Anlagenbaus sowie in der chemischen Industrie“, 4. Symposium „Informationstechnologien für Entwicklung und Produktion in der Verfahrenstechnik“. Berlin

\section{AuTHORS}

E. Blümel is with the Fraunhofer Institue for Factory and Automation, Sandtorstrasse 22, 39106 Magdeburg, Germany (Eberhard.Bluemel@iff.fraunhofer.de)

W. Termath is with the Fraunhofer Institue for Factory and Automation, Sandtorstrasse 22, 39106 Magdeburg, Germany (Wilhelm.Termath@iff.fraunhofer.de)

T. Haase is with the Fraunhofer Institue for Factory and Automation, Sandtorstrasse 22, 39106 Magdeburg, Germany (Tina.Haase@iff.fraunhofer.de)

Manuscript received 17 March 2009. Published as submitted by the authors. 